\title{
Fecal Estrone Sulfate Profile of a Sow Showing Abnormal Pregnancy with Fetal Mummification
}

\author{
Tadatoshi OHTAKI, Masaharu MORIYOSHI, Ken NAKADA and Toshihiko NAKAO \\ Department of Veterinary Obstetrics and Gynecology, Faculty of Veterinary Medicine, Rakuno Gakuen University, Ebetsu, Hokkaido \\ 069-8501, Japan
}

(Received 11 May 1999/Accepted 2 November 1999)

ABStRact. Fecal and plasma $E_{1} S$ of a sow with mummified fetuses, was compared with normal delivery cases. Fecal and plasma fluctuation patterns in $\mathrm{E}_{1} \mathrm{~S}$ were similar. In the sow with fetal mummification both fecal and plasma $\mathrm{E}_{1} \mathrm{~S}$ concentration rapidly decreased after day 80-90 compared to normal farrowing sows. This coincided with the estimated time of fetal death.—KEY wORDS: estrone sulfate, fetal mummification, swine.

J. Vet. Med. Sci. 62(3): 309-311, 2000

Mummification is common in the pig. Fetuses which die between days 40-90 of pregnancy are discharged together with normal ones at the time of delivery. The causes of mummification include heredity compression of the navel obi during gestation, damage to the placenta, infection and hormonal imbalances. To date, there has been no report on the endocrinological features of a sow with fetal mummification.

In pregnant sows, estrone sulfate $\left(E_{1} S\right)$ in peripheral blood is first detectable around day 16 of pregnancy and fluctuates with 2 peaks, one on days 23-30, and the other within a few days before parturition [12]. Robertson and King [12] suggested that $\mathrm{E}_{1} \mathrm{~S}$ concentration in maternal blood reflects the amount of estrogens synthesized and secreted by the blastocyst or feto-placental unit. Thus, early pregnancy diagnosis $[1,15,16]$ may be made by measuring $E_{1} S$ in maternal blood.

In a previous study [9], the authors measured $\mathrm{E}_{1} \mathrm{~S}$ in feces, which are easier to collect than blood, of sows. The study showed that changes in fecal and plasma $\mathrm{E}_{1} \mathrm{~S}$ were similar with a two day delay in fecal $\mathrm{E}_{1} \mathrm{~S}$ compared to plasma $\mathrm{E}_{1} \mathrm{~S}$.

This report describes a rare case in swine, a sow which delivered 4 mummified fetuses and one immature piglet. The $E_{1} S$ profile of this sow was compared with that of sows which delivered normal fetuses.

The sow was a hybrid (Large White $\times$ Landrace $\times$ Duroc), primiparaous and was one year six months old at the time of delivery. The sow had not been vaccinated against any diseases. It was kept in an individual stall and fed $2.4 \mathrm{~kg}$ per day of a commercially available compound feed for breeding sows (Power Breed ${ }^{\circledR}$, Chubu-Siryou Ltd. Co., Japan) and had $4 l$ of water per day. Estrus detection was performed daily by inspecting the vulva, checking for the standing reflex when pressed on the back, and contractility of the cervix uteri by palpation per rectum. The sow was artificially inseminated three times with a separating interval of $24 \mathrm{hr}$ on the days of displaying estrous signs with a commercially available liquid semen. Fecal and blood samples were collected at intervals of two days during pregnancy. Fecal samples were processed as described by Moriyoshi et al. [7] and Ohtaki et al. [9]. Briefly, an appropriate amount of impacted feces was taken from the rectum and immediately aliquoted in $2 \mathrm{~g}$ amounts. The aliquots were put in $8 \mathrm{~m} l$ of $0.01 \mathrm{M}$ phosphate buffer with $0.1 \%$ of bovine serum albumin (BSA; Sigma Chemicals Co., St. Louis, U.S.A.) and thoroughly mixed. The mixture then was centrifuged at $1,700 \times \mathrm{g}$ for $15 \mathrm{~min}$, and the supernatant was frozen at $-20^{\circ} \mathrm{C}$ until assayed for $\mathrm{E}_{1} \mathrm{~S}$. Blood samples were collected from the median tail vein into heparinized test tubes. Plasma was separated immediately by centrifugation $(1,700 \times \mathrm{g}, 15 \mathrm{~min})$ and kept at $-20^{\circ} \mathrm{C}$ until assayed for $\mathrm{E}_{1} \mathrm{~S}$. For comparison feces and blood were collected in the same way from 5 sows with normal delivery.

The assay procedure for fecal and plasma $E_{1} S$ was previously described by Ohtaki et al. [9], with estrone-3sodium sulfate as a standard (provided by Dr. A. Kambegawa; Kambegawa Laboratory, Japan), estrone sulfate ammonium salt $\left[6.7-{ }^{3} \mathrm{H}(\mathrm{N})\right]$ as a tracer (prepared by Daiichi Pure Chemicals Co., Ltd., Japan), and anti-estrone3 -sulfate rabbit serum (anti- $\mathrm{E}_{1} \mathrm{~S}$ serum). The anti- $\mathrm{E}_{1} \mathrm{~S}$ serum was generated by Cosmo Bio Co., Ltd., Japan with anti 6oxo-estrone-3-sulfate-6-CMO-BSA as the antigen. Cross reactivities of this antibody to estrone glucuronide, estrone, estradiol-3-sulfate, estradiol-3-glucuronide and estriol sulfate were $5.4,4.0,1.5,0.8$ and $0.8 \%$, respectively. The fecal $\mathrm{E}_{1} \mathrm{~S}$ assay had a sensitivity of $8.5 \mathrm{pg} /$ tube and the mean recovery rate was $95.0 \%$. The intra-assay coefficients of variation for the lowest (260 pg/g of fecal weight) and highest $\mathrm{E}_{1} \mathrm{~S}$ concentrations $(2,460 \mathrm{pg} / \mathrm{g}$ of fecal weight $)$ were 8.9 and $8.8 \%$, respectively. The inter-assay coefficients of variation for the lowest (258 pg/g of fecal weight) and highest $\mathrm{E}_{1} \mathrm{~S}$ concentrations $(2,352 \mathrm{pg} / \mathrm{g}$ of fecal weight $)$ were 10.7 and $14.2 \%$, respectively.

Pregnancy diagnosis was done using ultrasonography 22 days or more after the last insemination $[4,5]$, and the sow 
was judged pregnant. Purulent vaginal discharge was observed at 83 days of pregnancy, but the sow was not clinically ill. The sow was injected intramuscular with 10 mg dinoprost (Veterinary Pronalgon ${ }^{\circledR}$ F Injection, Pharmacia Upjohn, Ltd. Co., Japan) to induce parturition on day 116 of pregnancy, because no signs of parturition were observed through day 115 . On day 117 the sow farrowed a total of 5 piglets, one immature (female, birth weight $700 \mathrm{~g}$, placenta weight $89 \mathrm{~g}$ ) and 4 mummified fetuses (two male and two female). The mummified fetuses are shown in Fig. 1, the mean crown-rump length (CRL) and weight were $18.9 \mathrm{~cm}$ (range: 18.2-19.5) and $348 \mathrm{~g}$ (range: 330-362), respectively. The mummified fetuses had eyebrows and hard teeth. The cause of the mummification was not determined.

Five control sows had normal farrows (total litter size was 8-15). Changes in fecal and plasma $E_{1} S$ concentration of the normal farrowing sows and the sow with mummified fetuses are shown in Fig. 2. The data of the normal farrowing cases is the same in a previous report [9]. Mean $\mathrm{E}_{1} \mathrm{~S}$ concentration of normal farrowing cases in feces fluctuated exhibiting two peaks: the first peak was on days $28-32$, and from around days $72-82 \mathrm{E}_{1} \mathrm{~S}$ began to rise gradually reaching a second peak concentration on days 110-114. Changes in fecal $\mathrm{E}_{1} \mathrm{~S}$ showed a two-day delay compared to plasma $\mathrm{E}_{1} \mathrm{~S}$.

As shown in Fig. 2, fluctuations in $\mathrm{E}_{1} \mathrm{~S}$ were similar in feces and plasma for the mummification case. The first peak of $E_{1} S$ concentration was evident on day 28 in feces and on days 24-26 in plasma. $E_{1} S$ concentration in both feces and plasma remained at baseline levels during midpregnancy. However, it began to rise gradually from around days 72-76 in feces, and 68-74 in plasma. At 90 days of gestation fecal $\mathrm{E}_{1} \mathrm{~S}$ decreased from $1,447 \mathrm{pg} / \mathrm{g}$ and fluctuated between 274-800 pg/g until delivery. Similarly, plasma $\mathrm{E}_{1} \mathrm{~S}$ decreased from $1,875 \mathrm{pg} / \mathrm{m} l$ on day 88 and fluctuated between $411-880 \mathrm{pg} / \mathrm{m} l$ until delivery. Fecal and plasma $\mathrm{E}_{1} \mathrm{~S}$ concentrations on and after days 80-90 were remarkably lower than those of normal farrowing sows.

The delivery of 4 mummified fetuses and one immature piglet is rare in swine. Viral infection is the major cause of mummified fetuses. When there is only one or a few stillborn piglets in an otherwise normal litter, the likely cause is at farrowing, such as large litter size, prolonged farrowing, or anoxia. When stillbirths are part of a litter that also contains mummies, an infectious agent is more likely to be involved [14]. The causes of stillborns, mummifications and abortions are often difficult to ascertain.

Mean CRL and weight of the mummified fetuses was $18.9 \mathrm{~cm}$ and $348 \mathrm{~g}$, respectively. The fetuses probably died at day 80 of gestation because they had hair (e.g., eyebrows) and the milk teeth had callus (hardened teeth) $[2,6,8]$. Furthermore, a purulent discharge was observed at the vulva on day 83 of pregnancy, and this indicates the estimated time of fetal death. The $\mathrm{E}_{1} \mathrm{~S}$ concentrations in feces and plasma were also low around this time, especially after 90 days in this case, compared with normal parturition.

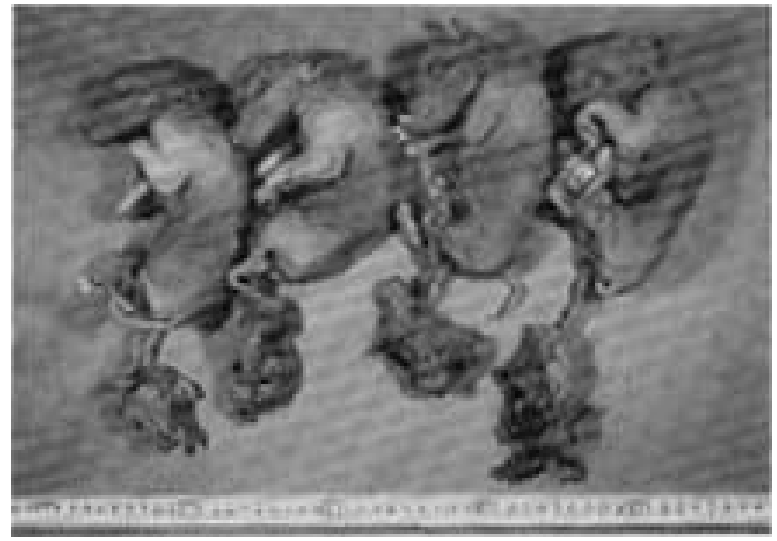

Fig. 1. Mummified fetuses after delivery (Note the similarity in size and weight).
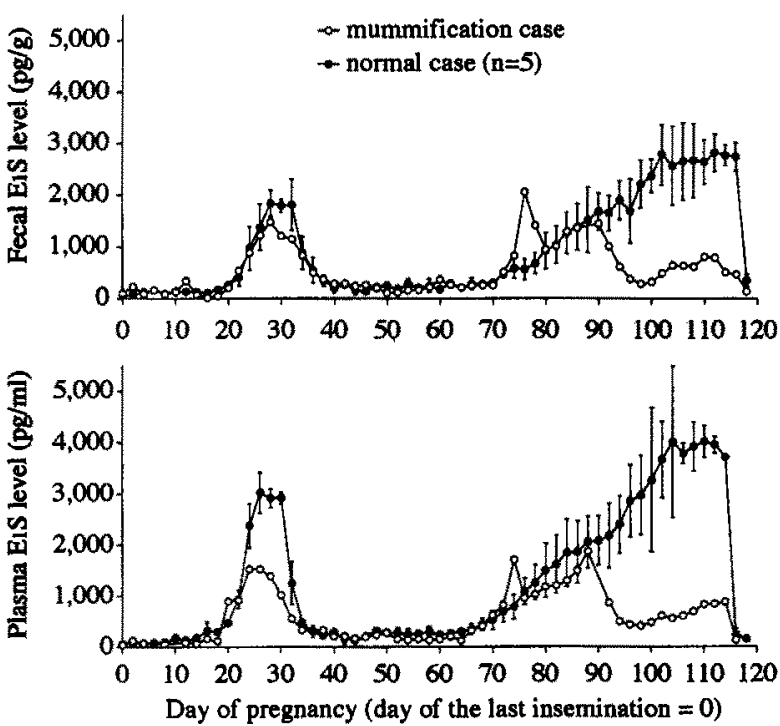

Fig. 2. Changes in fecal (top) and plasma (bottom) estrone sulfate $\left(\mathrm{E}_{1} \mathrm{~S}\right)$ concentration during pregnancy: mummification case $(\bigcirc)$, normal

A consequence of steroid synthesis in the preimplantation blastocyst is elevated concentrations of estrone and estradiol$17 \beta$ in the luminal fluid of the uterus. Although these unconjugated estrogens pass readily into the endometrium, their local tissue concentration is rapidly decreased by sulphotransferase, which results in the formation of estrogen sulphoconjugates with low biological activity [3, 10, 11]. Therefore, attempts have been made to make an early pregnancy diagnosis $[1,15,16]$ and estimation of litter size [13] by measuring the $\mathrm{E}_{1} \mathrm{~S}$ concentration in blood during early pregnancy.

The time of decrease in $\mathrm{E}_{1} \mathrm{~S}$ concentration in this study, coincided with the estimated time of fetal death. This probably resulted from a remarkable decrease in placental function. The mummified fetuses died around the same 
time, because their CRLs and weight were similar and they all had eyebrows and hard teeth.

In conclusion, this study showed a disparate $\mathrm{E}_{1} \mathrm{~S}$ profile in normal and mummified farrowing sows from insemination to parturition. This study is the first to report $E_{1} S$ concentrations of a sow with so many mummified fetuses, though it is only one case.

We are grateful to Dr. A. Kambegawa of Kambegawa Laboratory for the generous supply of $\mathrm{E}_{1} \mathrm{~S}$ standard.

\section{REFERENCES}

1. Cunningham, N. F., Hattersley, J. J. P. and Wrathall, A. E. 1983. Vet. Rec. 113: 229-233.

2. Evans, H. E. and Sack, W. O. 1973. Zentralbl. Veterinarmed., C. 2: 11-45.

3. Gadsby, J. E. and Heap, R. B. 1978. pp. 263-285. In: Novel Aspects of Reproductive Physiology. Medical and Scientific Books, New York.

4. Inaba, T., Nakazima, Y., Matsui, N. and Imori, T. 1983. Theriogenology 20: 97-101.

5. Irie, M., Ohmoto, K. and Kumagaya, S. 1984. Jpn. J. Zootech. Sci. 55: 381-388 (in Japanese with English summary).
6. Kawano, T. and Sakakibara, T. 1998. Jpn. J. Swine Sci. 35: 126-134 (in Japanese with English summary).

7. Moriyoshi, M., Nozoki, K., Ohtaki, T., Nakada, K., Nakao, T. and Kawata, K. 1997. J. Vet. Med. Sci. 59: 695-701.

8. Niwa, T., Mizuho, A., Fukushima, A. and Takahashi, A. 1954. Anim. Sci. Technol.(Jpn.) 25: 5.

9. Ohtaki, T., Moriyoshi, M., Nakada, K. and Nakao, T. 1999. J. Vet. Med. Sci. 61: 661-665.

10. Pack, B. A. and Brooks, S. C. 1974. Endocrinology 95: 16801690.

11. Perry, J. S., Heap, R. B., Burton, R. D. and Gadsby, J. E. 1976. J. Reprod. Fertil. (Suppl.) 25: 85-104.

12. Robertson, H. A. and King, G. J. 1974. J. Reprod. Fertil. 40: 133-141.

13. Stoner, C. S., Bazer, F. W., Thatccher, W. W., Wilcox, C. J., Combs, G. E., Knight, J. W., Wettemann, R. P. and White, C. E. 1986. Theriogenology 25: 709-720.

14. Straw, B. E. 1986. pp. 214-242. In: Diseases of Swine 6th ed., Iowa State University Press, Iowa.

15. Sugiyama, S., Nakao, T., Tsunoda, N. and Kawata, K. 1985. Br. Vet. J. 141: 60-68.

16. Tamamura, F., Kawata, K., Nakao, T. and Tsunoda, N. 1982. J. Coll. Dairying 9: 337-356. 